\title{
Paragraph-level Errors in Chinese Undergraduate EFL Learners' Compositions: A Cohort Study
}

\author{
Meihua Liu \\ Department of Foreign Languages and Literatures, Tsinghua University, China \\ Email: ellenlmh@gmail.com \\ Gehui Wang \\ Department of Foreign Languages and Literatures, Tsinghua University, China \\ Email: wanggehui@tsinghua.edu.cn
}

\begin{abstract}
The present study investigated the paragraph-level errors in 90 English compositions produced by 30 Chinese undergraduate non-English majors on three tasks during eight weeks. Analyses of these errors and the survey data yielded the following main findings: (1) Among the four categories of paragraph-level errors, errors in paragraph development accounted for the largest percentage, followed by errors in paragraph coherence, errors in paragraph unity, and inconsistency in point of view. This pattern was generally observed for the distribution of the errors in each individual task; (2) the errors generally tended to increase across tasks. Errors in paragraph development in particular increased statistically significantly in the last two tasks; (3) the errors of all categories were generally inversely correlated with the students' writing performance, among which errors in paragraph development were significantly inversely related to the latter, and (4) several reasons were identified for the errors such as the lack of writing practice and the influence of Chinese. Thus, it can be concluded that paragraph-level errors are often persistent in students' English writing and are closely related to the quality of the writing. They hence deserve further research.
\end{abstract}

Index Terms - paragraph, error, writing performance

\section{INTRODUCTION}

English writing, along with other basic skills (listening, reading and speaking), has always been an issue of great concern to EFL teachers and researchers. Despite the strong desire to write well in English, quite a number of Chinese university students still remain incompetent in English writing. Both students and teachers increasingly feel frustrated and complain about the quality of the learning outcome. For example, the writing part in the National College English Test Band 4 has always been a great difficulty to test takers, usually having the lowest average score among the four testing parts, well below the passing level (National Educational Examinations Authority and National College English Test Committee, 2009).

Errors, among all other English writing problems, have become the biggest headache to all sides that are involved: learners, teachers, raters or any other readers. Learners simply hate errors, believing that their writing would be better if without any errors. Teachers are not happy to see the errors made by their students either. But still, they want to know why students have made the errors and how they can help to improve the situation. Just like symptoms which are often used by doctors to diagnose a disease, the errors can also be deployed by teachers, researchers or even learners themselves to assess learners' writing in English. Instead of hating the errors, teachers and/or researchers usually choose to examine them to find out where the problem is. To be fair, errors actually provide teachers and/or researchers with a unique opportunity to gain insight into the mysterious process of L2 writing in the same way that symptoms contribute to the discovery of how the human body functions. Meanwhile, paper raters and the employers have been voicing their complaints about the large number of errors in the written English of college graduates, which clearly harms the fluency and clarity of the written pieces. As a result, errors, though much researched, still remain one of the most concerned issues in both SL/FL writing and acquisition. The present study aimed to analyze the paragraph-level errors in 90 English compositions produced by 30 Chinese undergraduate non-English majors on three tasks over a period of 8 weeks, their developmental patterns over three writing tasks, their correlations with the students' writing performance, and the sources for the errors.

\section{LITERATURE REVIEW}

In spite of the many criticisms on error analysis, such as the disagreement on what constitutes an error, how to identify an error, and how to classify errors, error analysis (EA) still remains the most systematic approach to investigate learner errors.

Over the decades, many researchers have attempted to define what an error is. For example, Corder (1967) referred to an error as a breach of code, a deviation from what was regarded as the norm; James (1998) defined an error as an 
unsuccessful bit of language; and Lennon (1991) regarded an error as a linguistic form or combination of forms which, in the same context and under similar conditions of production, would not be produced by the speakers' native speaker counterparts. Apparently, what is in common of these definitions is that they all define errors as a linguistic deviation. Recently, researchers have ventured to take a broader definition of an error to suit specific research purposes. For example, Zhang, Wu, Wang \& Zhang (1995) identified both linguistic errors and rhetoric errors, thus including not only grammatical problems but discourse problems in their study.

Since its boom in 1970s, numerous studies have been done to describe and categorize errors at sentence, paragraph and discourse levels (Cheng, 1994; Frantzen, 1995; Hyland \& Anan, 2006; Khuwaileh \& Shoumali, 2000; Kim, 2001; Tang, 2000). For example, Kim (2001) analyzed the errors in 60 Korean university EFL learners' summary writing and found that syntactic errors were the most damaging, followed closely by lexical errors. Cheng (1994) examined 455 errors in the English compositions produced by six first-year English majors and three second-year English majors from a Chinese university in Beijing. The researcher groups the errors into four categories (morphological, lexical, syntactic, and semantic errors) with several subcategories in each type and concluded that syntactic errors were the most serious, followed by semantic errors and morphological errors. Nevertheless, the researcher did not provide any scheme of classifying the errors or explain what constituted each type of the errors.

Gradually, research has come to orient more on specific types of errors in SL/FL writing, which has resulted in richer findings (Chan, 2004; Crompton, 2005; Crusan 2002; Dam, 2001; Feng, Ogata \& Yano, 2000; Ferris \& Roberts, 2001; French, 2005; Hinkel, 2001; Hsin, 2003; Huang, 2001; Liu \& Yang, 2006; Polio, 1997; Su, 2002). French (2005) explored the errors in 744 drafts composed by 248 students at Chukyo University to determine if there was a level of acceptance of errors because of the negative influence of the mother tongue, and if there was, whether these errors were becoming part of an accepted, standardized Japanese English. The results showed that there was little acceptance of third person -s, article and plural errors in student writing, but there was a measured degree of acceptance of in the following aspects: sentence combining and sentence fragments, omission of subject, generalizing or obscuring of subjects, and omission of expected superlatives. Zhang et al (1995) compared the writing performance of 138 non-English majors and 62 English majors of a Chinese university via a multiple choice test and an essay writing test. The results showed that the non-English majors did much better in the multiple choice task than in the writing task while the English majors did better the other way around, and that the non-English majors made far more errors in the writing task than the English majors did. In addition, they found that, for both English majors and non-English majors, rhetorical problems in their writing were much worse than grammatical problems.

As reviewed, the studies have generally revealed that syntactic and lexical errors are the most severe problems in learner's SL/FL writing. Even so, few studies have examined the errors across tasks over a longitudinal period of time or the relationship between the errors and students' writing performance in the target language. Moreover, fewer studies have focused on paragraph-level errors. Thus, the present study aimed to investigate the paragraph-level errors in 90 English compositions produced by 30 undergraduate non-English majors on three tasks over a period of 8 weeks. The following research questions are of particular interest:

(1) What is the general profile of the paragraph-level errors made by the university EFL students in their English writing?

(2) How do the errors develop in the three writing tasks over a period of eight weeks?

(3) How are the errors related to the students' writing performance?

(4) What are the general sources for the errors?

\section{RESEARCH DESIGN}

The present research was part of a larger project which aimed to explore errors at sentence, paragraph and discourse levels in the written compositions produced by Chinese undergraduate English learners.

Participants. 30 students from two natural English Writing classes consisting of 40 second-year non-English majors at a prestigious university in Beijing participated in the present study. Both classes lasted for 8 weeks, followed the same teaching plan, used the same teaching materials, conducted the teaching in the same procedure, and shared the same teaching assistant. With an age range from 19 to 21 and an average age of 20.3, the students were from various disciplines who were fairly proficient in English.

Instruments. To answer the four research questions, the present study collected the students' writing products and their scores on each product, and administered a survey, as detailed below.

The writing sample. The two English Writing classes were required to finish 4 writing tasks (free writing, letter writing, review writing, and argumentative writing) during the eight weeks. All the compositions, 120 pieces in total, produced by the 30 students were collected as potential samples for the present study. However, task B (letter writing) was excluded from the final analyses mainly because most students employed many fixed expressions or sentence structures in their writing, which resulted in 90 pieces as the valid samples for the present study. And since the students produced either expository or argumentative pieces on task A (free writing), expository essays on task $\mathrm{C}$ (review writing), and argumentative essays on task D (argumentative writing), all the compositions yielded by the students on the three tasks were expository or argumentative in nature. Thus the influence of genre on the errors the students made and their writing performance can be largely avoided. 
The survey. In order to gain the students' perceptions on the errors in their writing, a 13-item self-designed survey (see Appendix), together with 3 open-ended questions, was administered to them at the end of the eighth class, which was answered in 10 minutes. The questionnaire was written in Chinese and English to avoid confusion in understanding and covered the following two aspects: (1) general perspective on the difficulty of paragraph writing in English (items 1-5), and (2) perceptions on the possible causes for paragraph-level errors in their English writing (items 6-13). The survey was designed on a 5-point Likert scale ranging from 'Strongly disagree' to 'Strongly agree' with values 1-5 assigned to the descriptors respectively. In case the respondents might have other ideas about the difficulties and causes for the errors in their English writing, three open-ended questions were added to the survey.

English writing performance. All the participants' scores in the three writing tasks at different times during the eight weeks were collected respectively as their writing performance in the course.

Data analysis. The scheme of classifying written errors developed by Kramer, Leggett and Mead (1995) was employed in the present study. During the coding process, the first two researchers read every piece carefully and identified 1138 errors at various levels, of which 105 were paragraph-level errors, with an inter-rater reliability of .892. The coded errors were then entered into SPSS and analyzed in terms of frequency to reveal the general picture of the errors made by the students across tasks. After that, paired samples t-tests were run to identify the developmental patterns of the errors across tasks. Then, correlational analyses were conducted to examine how the errors were related to the student's writing performance. Meanwhile, the survey data were analyzed in terms of frequency and percentage to reveal the students' perceptions on the difficulties and possible causes for making paragraph-level errors in their English writing. The results were integrated into the description and discussion of the actual errors found in the writing pieces. Finally, the answers to the open-ended questions were analyzed and incorporated into the discussion of the errors.

\section{RESULTS AND DISCUSSION}

\section{A. General Profile of the Paragraph-level Errors}

1. General profile of the paragraph-level errors of the whole sample

Of 1138 identified errors in the 90 writing pieces on three tasks, 105 were paragraph-level errors, accounting for $9 \%$ of the total number of errors. These 105 errors were then grouped into four categories (P1-P4), as shown in Table 1, since according to Kramer et al. (1995), paragraphs are generally expected to have a unified topic, to be fully developed and to be coherent, no matter what the writing genre might be. Among the four types of paragraph-level errors, errors in paragraph development (P2) accounted for the largest percentage (43\%), followed by P3 (errors in paragraph coherence (28\%), P1 (errors in paragraph unity) (18\%), and P4 (inconsistency in point of view) (11\%). This implies that the participants had the biggest difficulty in paragraph development and paragraph coherence.

TABLE 1:

PARAGRAPH-LEVEL ERRORS OF THE WHOLE SAMPLE

\begin{tabular}{|l|l|}
\hline Types of paragraph-level errors & Number and percentage \\
\hline P1 (errors in paragraph unity) & $19(18 \%)$ \\
\hline P2 (errors in paragraph development) & $45(43 \%)$ \\
\hline P3 (errors in paragraph coherence) & $29(28 \%)$ \\
\hline P4 (inconsistency in point of view) & $12(11 \%)$ \\
\hline Total & $105(100 \%)$ \\
\hline
\end{tabular}

\section{Errors in paragraph unity}

The unity of a paragraph is derived from a controlling idea around which the paragraph is organized, a paragraph that lacks unity jumps from idea to idea, topic to topic, with no clear sense of purpose (Kramer et al., 1995). In the present study, errors in paragraph unity were defined as failing to show a controlling idea or having more than one controlling idea, or having a topic sentence that doesn't really control all the ideas in the paragraph. Altogether 19 (18\%) errors of this kind were coded in the study. The following were two examples excerpted from the students' writing.

(1) Charlie is a trier, but the ups and downs of his intelligence can serve as a reflection of our human society. Through his innocence, we can see the selfish and apathy of us normal people, and through his eminence, we can see the interest-oriented nature of us normal people. Sometimes, we should even learn from those mentally-retarded people and we are no superiority to them. The twisting plot, the eminence at a time, the up and down of a man's life, the poor mouse Algernon... All made this fiction a fascinating one! (Task B)

(2) The film described the life of the Sicilian back when movie was a new technology, showing how passionate the audiences were in watching films. However, the world changed, leaving the cinema less and less audience. In the end of the film, Salvatore went back to Sicily on hearing the death of Alfredo, only to see the dilapidated cinema being torn down. Seeing the moment it crashed, I could feel the sadness filled in the air. No complicated plots but touching, the film seemed a memorial of Sicily's past—rebuilt in the eye of Toto. (Task B)

In example (1), it seems that the writer intended to explain how the ups and downs of the main character's intelligence could serve as a reflection of the human society. And the following two sentences explained accordingly how the hero's IQ level before and after the experimental intelligence-improving surgery reflected the human society. 
However, the fourth sentence, also the last sentence in the paragraph, suddenly changed its direction, beginning to comment on the fiction - a fascinating one, which appeared as a new topic or idea, not so related to the controlling idea specified by the topic sentence (i.e., the first sentence), thus causing the paragraph to break apart.

Example (2) shows another problem in paragraph unity. The first three sentences seemed to indicate a brief summary of the story in the film, but the last two sentences introduced two different ideas: the writer's emotional reaction to the film (sentence 4) and the writer's comment on the film (sentence 5). So the paragraph generally covered three ideas, which were not strung together by a super-ordinate controlling idea of the paragraph. The paragraph thus lacked unity, which could be strengthened by either giving a topic sentence to cover the three ideas within the paragraph, or developing only one of the three ideas, leaving the other two to be developed in new paragraphs.

As such, the students seemed to have (much) difficulty in maintaining the unity of paragraphs in English writing. They might start the paragraph quite well, with a good topic sentence at the beginning, as shown in example (1). Nevertheless, as the writing continued, the topic sentence seemed to lose control gradually, more less related ideas crept in, finally diverting from the controlling idea. It almost seemed that once the topic sentence was out of sight (beyond certain numbers of sentences), the controlling idea was out of the writer's mind too (the topic sentence was totally forgotten). Another problem about paragraph unity common in the students' English writing was that the ideas were indeed related somehow, but due to the lack of a controlling topic sentence, the ideas scattered around loosely, thus damaging the unity of the paragraph.

For one thing, these problems in paragraph unity were probably generated by the lack of a proper writing outline before the writing started due to limited time or laziness. A proper outline of a paragraph provides focus and direction for the actual writing, therefore ensuring an overall view of the paragraph in advance and limiting the possibility of drifting off the focus during the process of actual writing. This hypothesis was actually supported by the students self-reports in the survey: $77 \%$ of the respondents (strongly) agreed that their paragraph lacked unity or focus because they just followed their instinctive thoughts during the actual writing (item 7). Namely, their pens went wherever their thoughts went, without a proper outline in mind or in paper in advance. The survey data also revealed that $54 \%$ of the respondents (strongly) disagreed with item 10 (it is not necessary to have a topic sentence for an English paragraph), denoting that most students did realize the importance of a topic sentence in a paragraph and had probably done so in their written compositions. However, the repeated occurrence of new ideas unrelated to the controlling idea in a paragraph suggested some students had (much) difficulty in achieving paragraph unity.

For another, the lack of a topic sentence to cover the ideas which were loosely linked in a paragraph might be due to the influence of Chinese writing. As suggested by Liu (1999), it has never been explicitly required to write something like a topic sentence for a paragraph in Chinese, though Chinese writing does require a focused topic in each paragraph. As to whether the focused topic is written out in the form of a topic sentence or is only implied, it doe not matter much; contrarily, it is often explicitly preferred to write out a topic sentence for each paragraph in English writing. Contradictory to this, $67 \%$ of the respondents (strongly) vetoed that their failure to provide a topic sentence for a paragraph was the result of Chinese influence, while only $23 \%$ believed so (item 8 ). Subtle as it is, it needs further research.

\section{Errors in paragraph development}

Paragraph development means that the controlling idea and any other subordinate ideas within a paragraph should be sufficiently explained or illustrated; a paragraph which lacks development is one that introduces a topic but fails to provide sufficient information to explain it to readers (Kramer et al., 1995). Accordingly, an error in paragraph development in the present study was defined as failing to supply enough explanation to a controlling topic, or a topic statement in the case of argumentative writing, or failing to supply the right information or related information needed to elaborate on the topic. $45(43 \%)$ errors of this kind were coded in the present study, meaning that most errors at the paragraph level existed in paragraph development. Consistent with this, the survey data revealed that $74 \%$ of the respondents (strongly) endorsed item 1 that they had (great) difficulty in developing a paragraph. The following are two examples.

(3) Plan earlier, fly higher: first year in the university is the very time to make a life-long career path, so you can get well prepared for the society before the graduation. (Task A)

(4) The emergence of projection contributed a lot to the revolution (of cinema) ---- motion pictures came out as the ultimate form of mass consumption. In the eyes of exhibitors, movies accompanied by other forms of entertainment were favored by the large audience, so we could easily find movies with live performance or the active involvement of a master of ceremonies. However, the substance of the movies themselves was mass-produced so that prerecorded material could be easily reproduced with little or no participation by the exhibitor. Finally, exhibitors were for this change. (Task C)

Example (3) started with a piece of advice to university freshmen, namely plan earlier, fly higher, which could well be perceived as the topic sentence of the paragraph. Upon reading this topic sentence, readers probably expected to read what plan earlier and fly higher meant and how to achieve the purpose in the first year. Surprisingly, nothing like this could be found thereafter. Thus, the writer failed to provide sufficient supporting details for the topic in this paragraph.

The writer of example (4) did try to explain the topic sentence (i.e., the emergence of projection contributed a lot of the revolution of cinema), but unfortunately, the explanation did not serve the purpose. What the writer actually 
explained in the rest of the paragraph was how movies accompanied by live performances came into being (sentence 2), how movies were produced at that time (sentence 3), and what were the exhibitors' attitudes towards the change (sentence 4), none of which was related to the contribution of the emergence of projection. The topic sentence was thus unsupported.

A careful reading of all the 90 pieces revealed that the lack of details and examples in developing paragraphs was in fact quite common among the students' English writing. Consistent with this, the survey data showed that $74 \%$ of the respondents (strongly) held that they had (great) difficulty in developing the topic sentence of a paragraph (item 1), and that $57 \%$ admitted that they often failed to provide sufficient details or examples to support a topic sentence (item 5). This difficulty of developing paragraphs might be attributed to two factors. One was the lack of adequate vocabulary, which consequently resulted in the students' diffidence in writing out details and concrete examples, since detailed description or narration often requires more specific words. Therefore, many students preferred to avoid details but stick to superficial explanation, with the purpose of avoiding making (more) lexical errors. The other factor might be the insufficient consideration of the reader's needs. Some students might be too self-involved in conducting the explanation, simply assuming that the reader would understand them and follow their reasoning. Unfortunately, it was always not the case. That is probably why a second voice is often needed during the writing or revising process, usually in the form of peer review. In addition, other factors such limited time, pressure or anxiety, students' laziness or ignorance of certain topics, and difficulty of the topic might contribute to the poor development of paragraphs in the students' English writing as well.

\section{Errors in paragraph coherence}

Paragraph coherence requires that the thoughts within a paragraph be linked together (Kramer et al., 1995). In this sense, coherence involves both positioning the ideas or sentences in a paragraph so that they can relate logically to one another, and using certain connecting devices to clarify relationships between the ideas (Kramer et al., 1995). Accordingly, an error in paragraph coherence was defined as an ineffective or illogical organization of the thoughts in a paragraph, or a failure to provide necessary or proper connecting devices between ideas in the present study. Altogether $29(28 \%)$ errors of this kind were coded in the present study, indicating that the students generally did not have much difficulty in achieving paragraph coherence. This was further supported by the students' self-reports on the survey. As shown in the Appendix, 37\% of the respondents reported that a proper organization of ideas in an English paragraph was a difficulty for them (item 2); 37\% thought they had trouble in making a paragraph coherent and logical (item 3); $20 \%$ admitted that they often made errors concerning paragraph organization (item 4); 33\% agreed that their writing often lacked necessary transitional markers (item 6); and 12 (40\%) students reported to have problems concerning paragraph coherence in their English compositions (item 15). Namely, most students were able to achieve coherence in paragraphs to varying degrees in their English writing.

The errors in paragraph coherence identified in the present study were mainly of three forms: ineffective organization of the ideas, the lack of transitional markers and the misuses of cohesive markers, as illustrated by the following two examples.

(5) But as a freshman, everything in the university was new and challenging for me. This was my first time to leave home and live in the school. At the beginning, I didn't feel habitable at all. I always missed my parents and looked forward to going back soon. There was some difficulty in my stud, too. I found that the calculus was difficult to learn. I couldn't get all what the teacher had said in the class. I had to spend much time in doing my homework. So I always felt very exhausted and upset. (Task A)

(6) This novel is so brilliant that almost every reader will fall in love with it as soon as they made contact with it. Nevertheless, I am sure about that as long as they know something about Jane Austen, they will fall in love with her too. (Task B)

The writer did a very good job in example (5) regarding paragraph unity and development in that both an effective topic sentence and sufficient details were provided in the paragraph. Nevertheless, when it comes to coherence, it was not that satisfying. For one thing, the details about the difficulties experienced by the writer were listed one after another, without a clear classification or order, which could actually fall into two groups: one related to the writer's homesickness and the other related to the difficulties in study. If so, a better and clearer organization would be achieved. For another, the details loosely scattered around in the paragraph, which needed to be linked together with effective cohesive devices. The following is a revised version of the example which demonstrates much higher coherence by grouping the details and adding some transitional markers.

But as a freshman, everything in the university was new and challenging to me. Homesickness and study were the two most difficult things. For one thing, since it was the first time I left home and lived in a school, I didn't get used to the life at all and always missed my parents, looking forward to going home all the time. For another, some courses such as Calculus were really difficult for me. I could not follow the teachers in class either. What's more, I had to spend much time in doing my homework. As a result, I always felt very exhausted and upset.

Some cohesive devices were deployed in example (6) to link the ideas together. However, the word nevertheless was clearly misused since no transition or contrast could be implied by the preceding and the following sentences.

Many factors could have contributed to some students' inability to achieve paragraph coherence in their English writing. As shown in the Appendix, around or more than 50\% of the respondents perceived lack of English writing 
practice (item 9) and insufficient knowledge about coherence in paragraph writing (item 11) as the main contributors to the loose organization and lack or misuse of transitional markers in their English writing. Compared with the concepts like unity and development, coherence is often considered to be more abstract. And some students even did not know the word coherence, let alone understand how coherence works or is achieved. As a result, even good writers might not do so well in maintaining paragraph coherence. The lack of writing practice might have also disabled some students to achieve paragraph coherence in their English writing. Meanwhile, 17\% of the respondents believed that the lack of paragraph coherence was because of the influence of Chinese (item 12). According to Zuo (1995), logic in Chinese is often realized by the semantic implications rather than the use of specific transitional markers. In other words, in Chinese, it is not necessary to provide specific cohesive markers to indicate the logic between ideas, as long as the logic can be inferred semantically. For example, it is quite all right in Chinese for several ideas to be listed individually without any logical linkers, as shown in the following paragraph in Chinese.

凡事都有两面性。塞翁失马焉知非福。想开了, 心情就会好些 (Zuo, 1995). (Literal English translation: Everything has two sides. Every cloud has a silver lining. If you can look at things in this way, you will be in a better mood.)

In this paragraph, the second sentence serves as an exemplified explanation of the first sentence, while the third sentence indicates a result that can be drawn from the first two ideas. Different from English, no logical linkers can be identified in the paragraph, yet the meaning can be easily comprehended.

Furthermore, the errors in paragraph coherence might be the result of writing as a writer-orientated process instead of a reader-orientated process. Ideas that are connected in the writer's mind may not seem obviously connected to the reader. Therefore, it is important for the writer to clearly mark the relationships between sentences and ideas. To do this, the writer has to organize his or her thoughts logically and to provide clear transitional markers to indicate any change in the flow of ideas in a paragraph. The pity is that many students were too preoccupied with expressing their own ideas to consider whether the reader could follow them.

\section{Inconsistency in point of view}

A unified, developed and coherent paragraph can still fail if it is not consistent within itself in terms of point of view (Kramer et al., 1995). If information is being reported from the writer's point of view, the reader expects that point of view will continue throughout the paragraph. In the present study, an error in the consistency in point of view was defined as the wrong shift in person, tense or number between sentences within a paragraph, for these wrong shifts could make the reader confused about who was speaking and to whom (person), what the time sequence was (tense), and how many were being talked about (number). The following are some typical examples.

(7) What's more, people who are always late make themselves look selfish, they may be alienated by others. In a word, to be late can both confuse the life of others and destroy your life. Remember to be on time next time! ... (Task A)

(8) Judy was brought up in an orphan asylum. One of the trustees of the asylum, who remains unknown to Judy, offered to pay her way through college including her tuition and monthly allowance when she was eighteen-year-old. The trustee plans to educate her to be a writer and the writing of monthly letters is the only thing he requires...(Task B)

Example (7) discussed the consequences of being late. At the beginning, the writer used the plural third person form, people and they, to refer to his or her target in criticizing unpunctuality. This was in fact a good strategy in that this would make the reader side with the writer. However, in the second and the last sentences, the writer suddenly changed to your and you, directing the criticism suddenly to the reader. This unwise change in person reference upset the reader, making him/her feeling offended. Example (8) showed an inconsistency in tense as indicated by the underlined parts in the paragraph. The shift between past and present tense indicated a disorder in time sequence in the paragraph, thus confusing the reader.

A shift in person, tense or number is necessary under certain circumstances, which may help to clarify who is talking or who is being talked about, and what is taking place. However, an unnecessary/wrong shift in these three aspects proves to be confusing and/or distracting to readers, making it (more) difficult for them to understand the writing.

The present study identified $12(11 \%)$ errors of inconsistency in point of view, of which 5 were concerned with wrong shift in tense, 4 in number, and 3 in person.

All the five shifts in tense occurred in Task C (review writing) where a story in a film or in a book was summarized, which indicated that some students were unsure about what tense should be used in reporting a fiction story. And this uncertainty was most likely caused by the fact that the story in the film or book is usually told in past tense, while the book or the film itself remains a general fact in reality. The four coded errors in shift in number all involved the wrong shift between the third person single form and the third person plural form, which was probably caused by the understanding that a category can be realized by both the whole population and a single specimen from the category. For example, when the category of engineers is to be talked about, both the expression engineers and the expression an engineer can be used. Alternatively, both of the sentences Engineers are usually very busy people and An engineer is usually a very busy person actually mean the same thing. Therefore, with such knowledge in mind, the students firmly believed that there was nothing wrong in saying University graduates often have trouble in finding a good job for themselves. ... What a student has learned in school is often considered out of date in society.... However, the students failed to understand that even though the above two sentences mean the same thing, the two person references, namely engineers and an engineer, are seldom used together in one paragraph or even in one essay to indicate the category. The convention requires only one be used consistently throughout the whole paragraph or the whole essay. All the three 
wrong shifts in person happened in task A (free writing) when the writer was the witness of or the person who experienced what happened or was described in the writing. Instead of sticking to the first or third person point of view when narrating what happened, the writer shifted between the two, thus confusing the reader. The following excerpt is a good example.

The students in Tsinghua University are too lucky to have so many students' clubs and associations. You may think they are distractions for our study. In fact, if you join the right club, it can help you a lot in study... (Task A)

2. General profile of the paragraph-level errors in individual tasks

As noted from Table 2, in each individual task, errors about consistency in point of view (P4) (9\%, $13 \%$ and $12 \%$ for tasks A, C, and D respectively) were the least frequently made; errors in paragraph coherence (P3) (59\%) were predominant in task A while errors in paragraph development (P2) (59\%) were predominant in task D; and P1, P2 and P3 displayed an even distribution in task C. This suggests that the participants had the biggest difficulty in paragraph development and paragraph coherence, conformant with the finding of the whole sample.

TABLE 2:

PARAGRAPH-LEVEL ERRORS IN INDIVIDUAL TASKS

\begin{tabular}{|l|l|l|l|}
\hline Type of paragraph-level errors & Task A & Task C & Task D \\
\hline P1 & $4 / 18 \%$ & $7 / 29 \%$ & $8 / 14 \%$ \\
\hline P2 & $3 / 14 \%$ & $7 / 29 \%$ & $35 / 59 \%$ \\
\hline P3 & $13 / 59 \%$ & $7 / 29 \%$ & $9 / 15 \%$ \\
\hline P4 & $2 / 9 \%$ & $3 / 13 \%$ & $7 / 12 \%$ \\
\hline Total: & $22 / 100 \%$ & $24 / 100 \%$ & $59 / 100 \%$ \\
\hline
\end{tabular}

\section{B. Developmental Patterns of the Errors across Tasks}

A cross-comparison of the errors reported in Table 2 shows that, among the three tasks, task A yielded the largest number of errors in paragraph coherence (P3), and task D had the largest number of errors in paragraph unity (P1), paragraph development $(\mathrm{P} 2)$, and inconsistency in point of view (P4). Meanwhile, Table 2 shows that the total number of paragraph-level errors increased to be 24 in task C and 59 in task D from 22 in task A. A similar pattern was observed for such specific types of paragraph-level errors as P1 (4, 7 and 8 for tasks A, C, and D respectively), P2 (3, 7 and 35 for tasks A, C and D respectively), and P4 (2, 3, and 7 for tasks A, C, and D respectively). The number of P3 decreased to be 7 in task $\mathrm{C}$ from 13 in task $\mathrm{A}$ and then increased to be 9 in task D. It seems that the participants tended to commit more paragraph-level errors in tasks $\mathrm{C}$ and $\mathrm{D}$. This might be because paragraph writing was less a focus than sentence writing in class during the course. Nevertheless, not all the differences were significant, as proved by the paired samples t-tests results reported in Table 3.

TABLE 3:

RESUlTS OF PAIRED SAMPLES T-TESTS

\begin{tabular}{|c|c|c|c|c|c|c|}
\hline \multirow{2}{*}{ Type of errors } & \multicolumn{2}{|c|}{ Tasks A vs C } & \multicolumn{2}{c|}{ Tasks A vs D } & \multicolumn{2}{c|}{ Tasks C vs D } \\
\cline { 2 - 7 } & $\mathrm{t}$ & $\mathrm{p}$ & $\mathrm{t}$ & $\mathrm{p}$ & $\mathrm{t}$ & $\mathrm{p}$ \\
\hline P1 & .902 & .375 & .94 & .354 & .205 & .839 \\
\hline P2 & 1.44 & .161 & $\mathbf{5 . 5 7}$ & .000 & $\mathbf{4 . 8 8}$ & .000 \\
\hline P3 & -1.65 & .110 & -.891 & .380 & .441 & .662 \\
\hline P4 & .372 & .712 & 1.22 & .231 & 1.28 & .211 \\
\hline Total & .403 & .710 & $\mathbf{5 . 6 1}$ & .000 & $\mathbf{5 . 5 9}$ & .000 \\
\hline
\end{tabular}

Table 3 shows that significant difference occurred in P2 (paragraph development) $(\mathrm{t}=5.57, \mathrm{p}=.000)$ and overall paragraph-level errors $(t=5.61, p=.000)$ between tasks $\mathrm{A}$ and $\mathrm{C}$. It was the same when tasks $\mathrm{C}$ and $\mathrm{D}$ were compared $(t=4.88$ and 5.59 for $\mathrm{P} 2$ and overall paragraph level errors respectively, $\mathrm{p}=.000)$. Alternatively, compared with task $\mathrm{A}$, the participants made significantly more paragraph-level errors and errors in paragraph development in task $\mathrm{C}$, and in task D when compared with task C. Namely, these errors were not only persistent, but going from bad to worse, which is hence worth further research.

\section{Correlations between the Errors and Students' Writing Performance}

To determine how the paragraph-level errors were correlated with the students' writing performance, correlation analyses were run. The results are presented in Table 4.

TABLE 4:

CORRELATIONS BETWEEN THE ERRORS AND WRITING PERFORMANCE

\begin{tabular}{|l|l|l|l|l|l|}
\hline & $\mathrm{P} 1$ & $\mathrm{P} 2$ & $\mathrm{P} 3$ & $\mathrm{P} 4$ & Total \\
\hline $\mathrm{A}$ & -.018 & -.014 & -.237 & -.013 & -.261 \\
\hline $\mathrm{C}$ & -.218 & -.217 & -.206 & -.168 & -.262 \\
\hline $\mathrm{CD}$ & -.214 & $-.363^{*}$ & -.217 & -.219 & $-.371^{*}$ \\
\hline
\end{tabular}

$\mathrm{A}, \mathrm{B}, \mathrm{C}=$ students' scores in writing tasks $\mathrm{A}, \mathrm{B}$ and $\mathrm{C}$ respectively 
As shown in Table 4, overall paragraph-level errors, as well the four specific categories of paragraph-level errors, was inversely related to the students' performance in all the three tasks. Among the correlations, P2 (paragraph development $)(\mathrm{r}=-.363)$ and overall paragraph-level errors $(\mathrm{r}=-.371)$ were significantly negatively correlated with the students' performance in task D. In other words, the weaker a writer was at developing a paragraph, the worse s/he performed in a writing task, the more paragraph-level errors a writer made, the worse s/he performed in a writing task; or vice versa.

\section{CONCLUSIONS AND IMPLICATIONS}

The present study examined the paragraph-level errors in 90 compositions written by 30 Chinese undergraduate EFL learners on three tasks during eight weeks. Analyses of the compositions yielded 105 paragraph-level errors grouped into four categories, among which errors in paragraph development accounted for the largest percentage, followed by errors in paragraph coherence, errors in paragraph unity, and inconsistency in point of view. This pattern was generally observed for the distribution of the errors in each individual task. A cross-comparison of the errors across tasks shows that the students tended to make more paragraph-level errors in tasks C and D. Errors in paragraph development in particular increased statistically significantly in tasks C and D. Correlation analyses revealed that the paragraph-level errors of all categories were negatively correlated with the students' performance in each writing task, among which errors in paragraph development were significantly inversely related to the latter. Meanwhile, a number of causes for the errors such as lack of writing practice and the influence of Chinese were identified and discussed.

As discussed in the paper, 105 paragraph-level errors were identified, accounting for $9 \%$ of the total number of errors of all kinds in the 90 pieces, meaning that paragraph-level errors were not a big problem for the participants. Even so, since these errors proved to be inversely related to the students' writing performance and some were persistent across tasks, they are worth further research on how to help students write more effective paragraphs and ultimately improve the quality of their English writing. Meanwhile, the findings of the present study show that the teaching and training of English writing at the tertiary level should focus on paragraph writing as well, thus enabling them to make less paragraph-level errors across tasks over a long period of training. As students, it is beneficial for them to be aware of the difference between Chinese and English and try their best to avoid the negative influence of their mother tongue and write English in the mainstream style. At the same time, it is better for them to practice more writing and be more careful when writing in English.

\section{APPENDIX: PERCEPTIONS OF THE DIFFICULTIES AND PARAGRAPH-LEVEL ERRORS IN ENGLISH WRITING}

Directions: This survey aims to explore students' perceptions of the difficulties and paragraph-level errors in their English writing. Please read the statements carefully and choose an alternative that suits you best from the five choices: $\mathrm{SD}=$ Strongly disagree; $\mathrm{D}=$ Disagree; $\mathrm{N}=$ Not sure; $\mathrm{A}=$ Agree; $\mathrm{SA}=$ Strongly agree. All the data collected herewith will be used for research only.

Name:

Gender:

Age: 


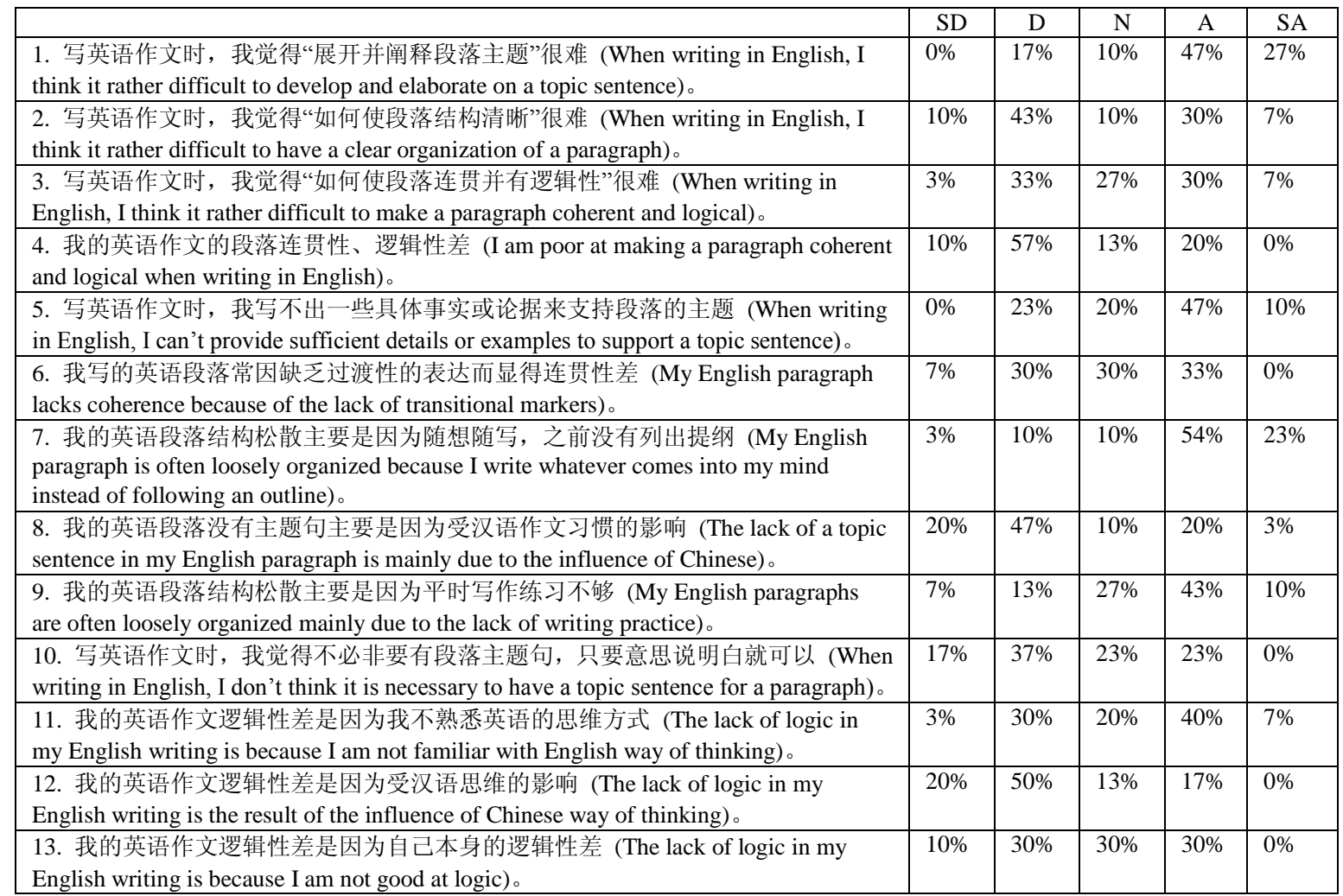

14. 写英语作文时, 我感觉最难的是 (When writing in English, I feel the greatest difficulty lies in)

15. 写英语作文时, 我常犯的错误有 (When writing in English, the errors I often make are)

16. 我的英语段落结构松散主要是因为 (The loose organization of my English paragraphs is mainly because of)

\section{ACKNOWLEDGEMENT}

The present study was sponsored by the Humanities and Social Science Revitalization Fund Research, Tsinghua University (No.: 2010WKYB019).

\section{REFERENCES}

[1] Chan, A. Y. W. (2004). Syntactic Transfer: Evidence from the Interlanguage of Hong Kong Chinese ESL Learners. The Modern Language Journal, 88(1), 56-74.

[2] Cheng, J. (1994). On the teaching of English writing. Foreign Language Teaching and Research, 98(2): 12-18.

[3] Corder, S. P. (1967). The significance of learners' errors. International Review of Applied Linguistics, 5, 161-169.

[4] Crompton, P. (2005). "Where", "In which", and "in that": a corpus-based approach to error analysis. RELC Journal, 36, 157-176.

[5] Crusan, D. (2002). An assessment of ESL writing placement assessment. Assessing Writing, 8(1), 17-30.

[6] Dam, P. (2001). Old habits die hard: persistent errors in English written by Vietnamese speakers. Retrieved on March 10, 2011 from http://www.quangio.com/quangio/damtrungphap1101.htm.

[7] Feng, C., Ogata, H., \& Yano, Y. (2000). Mark-up-based writing error analysis model in an on-line classroom. Computer Assisted Language Learning, 13(1), 79-97.

[8] Ferris, D., \& Roberts, B. (2001). Error feedback in L2 writing classes: how explicit does it need to be? Journal of Second Language Writing, 10(3), 161-184.

[9] Frantzen, D. (1995). The effects of grammar supplementation on written accuracy in an intermediate Spanish content course. Modern Language Journal, 79, 329-344.

[10] French, G. (2005). The cline of errors in the writing of Japanese university students. World Englishes, 24(3), 371-382.

[11] Hinkel, E. (2001). Matters of cohesion in L2 academic texts. Applied Language Learning, 12(2), 111-132.

[12] Hsin, A.C. (2003). Indefinite subject NPs between English and Chinese: an error analysis. Retrieved on March 15, 2011 from http://www.cal.org/ericcll/releaseform.html

[13] Huang, L. S. (2001). Knowledge of English collocations: an analysis of Taiwanese EFL learners. Texas papers in Foreign Language Education: Selected Proceedings from the Texas Foreign language education Conference, 6(1), 256-264.

[14] Hyland, K. \& Anan, E. (2006). Teachers' perceptions of error: The effects of first language and experience. System, 34(4), 509-519. 
[15] James, C. (1998). Errors in language learning and use. Addison Wesley: Longman Inc.

[16] Khuwaileh, A. A., \& Shoumali, A. A. (2000). Writing errors: a study of the writing ability of Arab learners of academic English and Arabic at university. Language, Culture, and Curriculum, 13(2), 174-183.

[17] Kim, S. A. (2001). Characteristics of EFL readers' summary writing: A study with Korean university students. Foreign Language Annals, 34(6), 569-581.

[18] Kramer, M.G., Leggett, G., \& Mead, D. (1995). Prentice Hall Handbook for Writers. Englewood Cliffs, NJ: Prentice Hall.

[19] Lennon, P. (1991). Error: some problems of definition, identification, and distinction. Applied Linguistics, 12(2), $180-196$.

[20] Liu, C., \& Yang, S. (2006). A study on the misuse of words among Chinese EFL learners. Foreign Language World, 8(4), 301-304.

[21] Liu, L. (1999). A contrastive study of English and Chinese discourse patterns. Modern Foreign Languages, 4, 24-34.

[22] National Educational Examinations Authority and National College English Test Committee. (2009). Retrieved on Dec. 21, 2010 from http://www.edu.cn/20051222/3167199.shtml.

[23] Polio, C. G. (1997). Measures of linguistic accuracy in second language writing research. Language Learning 47(1), $101-143$.

[24] Su, H. (2002). Error analysis of the transitional verbs produced by Chinese EFL learners. Foreign Language Teaching, 23(1): 36-41.

[25] Tang, L. (2000). Error analysis on the written expressions produced by Chinese EFL Learners. Foreign Languages and their Teaching, 12, 56-61.

[26] Zhang, Z., Wu, H., Wang, X., \& Zhang, J. (1995). Main problems about the teaching of English writing in China. Foreign Language Teaching and Research, 104(4), 43-50.

[27] Zuo, Y. (1995). Differences in cohesive devices used in Chinese and English discourses. Foreign Language Teaching and Research, 3, 21-29.

Meihua Liu is associate professor of English at the Department of Foreign Languages and Literatures, Tsinghua University, China. Her research interests mainly include second/foreign language teaching and learning, reticence and anxiety, language attitudes and motivation, and second language writing.

Gehui Wang is lecturer of English at the Department of Foreign Languages and Literatures, Tsinghua University, China. Her major research interests include EFL teaching and learning and EFL writing. 